\title{
Article \\ The Effect of the Selection of Three-Dimensional Random Numerical Soil Models on Strip Foundation Settlements
}

\author{
Kamil Żyliński ${ }^{1,2}$, Karol Winkelmann ${ }^{1, *}$ (C) and Jarosław Górski ${ }^{1}$ \\ 1 Faculty of Civil and Environmental Engineering, Gdańsk University of Technology, Narutowicza 11/12, \\ 80-233 Gdańsk, Poland; kamil.zylinski@pg.edu.pl or kamil.zylinski@midroc.pl (K.Ż.); jgorski@pg.edu.pl (J.G.) \\ 2 Midroc Rodoverken Production, Hoffmana 4, 86-131 Gródek, Poland \\ * Correspondence: karolwin@pg.gda.pl; Tel.: +48-668-170-743
}

check for updates

Citation: Żyliński, K.; Winkelmann,

K.; Górski, J. The Effect of the

Selection of Three-Dimensional Random Numerical Soil Models on Strip Foundation Settlements. Appl. Sci. 2021, 11, 7293. https://doi.org/ 10.3390/app11167293

Academic Editor: Cecilia Surace

Received: 1 July 2021

Accepted: 5 August 2021

Published: 8 August 2021

Publisher's Note: MDPI stays neutral with regard to jurisdictional claims in published maps and institutional affiliations.

Copyright: (C) 2021 by the authors. Licensee MDPI, Basel, Switzerland. This article is an open access article distributed under the terms and conditions of the Creative Commons Attribution (CC BY) license (https:// creativecommons.org/licenses/by/ $4.0 /)$.

\begin{abstract}
This paper delivers a probabilistic attempt to prove that the selection of a random threedimensional finite element (FE) model of a subsoil affects the computed settlements. Parametric analysis of a random soil block is conducted, assuming a variable subsoil Young's modulus in particular finite elements. The modulus is represented by a random field or different-sized sets of random variables; in both cases, the same truncated Gaussian model is assumed. Mean values and standard deviations of random soil settlement are estimated by a Monte Carlo simulation procedure. With regard to the adopted FE model, the estimated settlement mean values do not vary significantly, but standard deviations do strongly. Similarities also appear in the diagrams of random field correlation length versus settlement standard deviation and the diagrams displaying a total number of model random variables versus settlement standard deviation. Thus, relevant single random variable models represent the random field approach well with regard to settlement parameter estimation. This remark is verified upon a settlement analysis of a three-dimensional FE model of a hypothetical strip foundation. Following the preliminary model observations, various probabilistic geotechnical analyses may be supported, e.g., continuous footing design, slope stability analysis, and foundation reliability assessment.
\end{abstract}

Keywords: soil FE modelling; Monte Carlo material model; three-dimensional random fields; strip foundations; settlements

\section{Introduction}

Soil medium displays an inherent material parameter variability. Numerical modelling of actual spatial soil variability is a considerable task, even when extensive in situ tests are carried out at the construction site. Hence, the only way to relevantly capture the uncertainty of subsoils leads to probabilistic methods. A strong recommendation for random methodology is now active, and the standards, e.g., Eurocodes, follow this. A direct introduction to the probabilistic approach in standard engineering computations is a present-day requirement and a future development perspective in the field [1-3].

Probabilistic methods are extensive due to the enormous development of computational power, introducing advanced finite element analysis (FEA) software to solve numerical problems of the subsoil media. Both the bearing capacity of foundations in their limit states (ultimate limit state-ULS) and the assessment of settlements (serviceability limit state-SLS) employ probabilistic analytical means. An extensive literature review in the field is presented in, e.g., [4], including the application of structural reliability analysis (SRA) and the stochastic finite element method (SFEM) to geotechnical problems. However, the classical Monte Carlo (MC) simulation method is the most frequent, as it is easy in numerical implementation, widely available in the software market, and simple in the interpretation of its results. Many MC variance reduction techniques are developed on a high scale, e.g., stratified sampling and Latin hypercube sampling [5]. The MC simulation method is fundamental in reliability-based robust geotechnical design (RGD) [6]. 
The first-order reliability methods (FORM) and second-order reliability methods (SORM) are permanently developed [7]. Note that numerical results are affected by the chosen computational method and are possibly different from the in situ measurements $[8,9]$.

There are various ways to reflect uncertainty in soil medium parameters. The most advanced and challenging, in theoretical and numerical meaning, is the random field approach in both two-dimensional and three-dimensional versions (see, e.g., [10,11]). A joint approach of multi-block failure mechanisms and a spatial averaging approach is shown in [12]. Kasama and Whittle [13] proposed the upper-bound and lower-bound analysis. Generation based on the Karhunen-Loeve expansion method and the classic exponential covariance function method is presented in [14]. Advanced correlation functions and the Weibull-type variables are incorporated in [15]. Al-Bittar and Soubra [16] applied polynomial chaos expansion in bearing capacity assessment of a strip foundation; material parameter sensitivity is analysed with the use of the Sobol index here. Similar solutions are adopted in [17]. Al-Bittar et al. [18] combined advanced kriging and Monte Carlo simulation (AK-MCS). Ali et al. [19] combined the FEM adaptive techniques with random field application. The point estimate method (PEM) is also applied (see [20]). Suchomel and Mašín [21] employed studies on the in situ results in the parameter estimation of the random field correlation function. Regardless of the adopted approaches, it is necessary to apply advanced computational algorithms, unavailable in commercial software; hence, implementation difficulties arise in real-life engineering cases.

Random fields are essential in the uncertainty modelling of a subsoil based on limited in situ data [22,23]. Attempts are made to precisely model the subsoil medium in twodimensional [24] or three-dimensional [25] problems. Material homogenization allows for realistic subsoil modelling [26,27]. The methods above are often applied in specific cases, e.g., column-reinforced soils $[28,29]$. Ching et al. [30] proposed to simulate the subsoil Young's modulus using a homogenization procedure linking the probabilistic FE analysis and the homogeneous FE analysis.

This paper proposes an alternative subsoil modelling to reflect the uncertainty of material parameters. The novel approach is relatively simple and straightforward, ready for direct application in FE models. It replaces complex probabilistic material models with simple yet effective computational algorithms.

Parametric analysis is performed on a loaded spatial soil block, representing the subsoil of uncertain response. The settlement of the central point of the upper block surface is analysed in a computational series. Several modelling cases are analysed, although the same material definition concerns every model. The change of settlement mean value and standard deviation in the series is investigated. The first computational stage defines material variability by a standard three-dimensional random field. The parameters of the field correlation functions affect the central point settlement. An alternative, simplified version is then introduced, with direct use of FEM elements. Here, the subsoil is modelled by a single random parameter and sets of random parameters of specific sizes. The FE model definition of the soil acts strongly on the numerical output. The proposed simplified overview of the block effectively represents a mechanical response of the subsoil.

In the second part of the paper, the settlement of a hypothetical strip foundation was analysed for selected FE models. These models do not map the subsoil precisely; instead, they represent the real-life geotechnical design conditions to approximate the global random response of the foundation-loaded subsoil. It was confirmed that a different approach to FE modelling is bound to yield various results regardless of identical material definition.

The paper is not a case study analysis. It presents possible approaches to probabilistic modelling, featuring soil parameter definition by a simplified approach, directly linking material parameters to corresponding finite elements. In the authors' opinion, the conclusions may be interesting to designers as they constitute warnings and guidelines to the analysis of loaded soils of uncertain response. The paper delivers valuable information on the mechanical response variability of the subsoil, impossible to find in the deterministic analysis. 


\section{Random Spatial FE Models of the Subsoil}

The issue of the numerical uncertainty definition of the subsoil is analysed in various FE models of a spatial subsoil block presented in Figure 1. The analysis is performed in ZSoil ${ }^{\circledR}$ software [31-33] coupled with Python ${ }^{\circledR}$ programming language [34] to aid the series of repetitive parametric computations. The representative random subsoil volume area is modelled as a block with dimensions of $10 \times 10 \times 10 \mathrm{~m}$ (all finite elements have dimensions equal to $1 \times 1 \times 1 \mathrm{~m}$ ), distinguished in pink in Figure 1 .

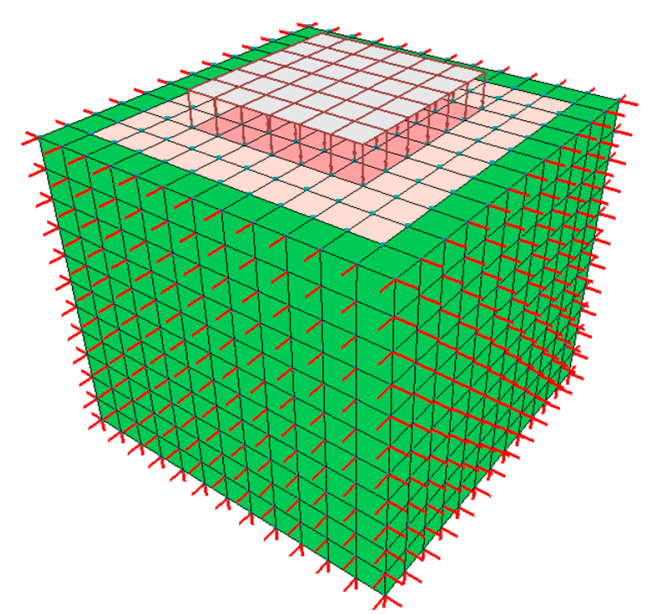

Figure 1. The FE model of the subsoil block, featuring the adopted indirect loading.

The boundary conditions at the interface with the surrounding subsoil are reflected by an additional layer of elements whose Young's modulus is $E_{b c}=560 \mathrm{kPa}$ and Poisson's ratio is $v_{b c}=0.25$, distinguished in green in Figure 1.

These parameters are established based on a preliminary numerical test. First, a simple compression test of the boundary element stratum is performed, assuming Young's modulus $E_{b c, t}=60,000 \mathrm{kPa}$ and Poisson's ratio $v_{b c, t}=0$, so that the boundary element soil stratum does not contribute to lateral displacements of the main subsoil block. The lateral displacement of the boundary layer $\delta_{b c}=0.000803 \mathrm{~m}$ is determined. Subsequently, this value is substituted as the target lateral displacement of the global subsoil block FE model, with the lateral contribution $\left(v_{b c}=0.25\right)$ of the boundary layer assumed. This allows determining the required effective stiffness parameter of the boundary layer as $E_{b c}=560 \mathrm{kPa}$, ensuring proper subsoil deformability in all directions.

The total number of finite elements is equal to $n_{\text {el,tot }}=12 \times 12 \times 11=1584$, whereas only $n_{e l}=10 \times 10 \times 10=1000$ constitute the regarded subsoil. The subsoil loading $q=170 \mathrm{kPa}$ is situated on the soil block indirectly, represented by a flexible metal sheet (plate) with a width $w=6.0 \mathrm{~m}$, thickness $t=0.01 \mathrm{~m}$, and material parameters corresponding to S235 steel (Young's modulus $E_{s}=210 \mathrm{MPa}$, Poisson's ratio $v_{s}=0.30$ ). The subsoil is governed by the Coulomb-Mohr material model.

In the task, the Young's modulus of the subsoil $E$ is considered the only random variable, with a Gaussian probability density function (PDF) of the mean value $\mu_{E}=28,000 \mathrm{kPa}$ and standard deviation $\sigma_{E}=7000 \mathrm{kPa}$. While the coefficient of variation is $v=0.25$, there is a $0.00317 \%$ probability that the generated $E_{i}$ value will be negative; therefore, a truncation parameter of $t=4.0\left(E_{i} \in \mu_{E} \pm t \sigma_{E}\right)$ is introduced, and hence no negative Young's moduli appear in the subsequent generation.

Note that a relatively large Young's modulus variability of the subsoil was purposefully assumed to introduce a significant impact on the scatter of the numerical results of the settlements. Thus, the random variable distribution is not realistic. However, in most design cases in real-life engineering, the data on subsoil variability acquired from the in situ surveys are limited. Hence, suggestions in design codes and literature guidelines vicariously reflect the random parameters, adopting their high variability. As an example, 
variability $v=0.3$ is incorporated in the reliability assessment of foundations resting on piles [35] or in stability analysis of a coastal cliff [36].

Both cohesion $c=10 \mathrm{kPa}$ and internal friction angle $\phi=30^{\circ}$ are assumed deterministic but, in fact, can be assumed random. The algorithms proposed in the paper do not limit the number of material parameters to be considered random variables. However, to compare the influence of the adopted FE models on the variability of the computed settlements, Young's modulus $E$ is assumed the only random variable.

Various random FE models of the subsoil block are assembled in the ZSoil ${ }^{\circledR}$ software, representing the global randomness of the FE model in different ways. Upon a given number of crude Monte Carlo simulations, all FE models examine the positive displacement of the central node of the upper (loaded) subsoil block surface (under the centre of the metal sheet transmitting the uniformly distributed load). The mean values and standard deviations of the central node displacement are investigated.

\subsection{The Subsoil Material Parameters Described by Three-Dimensional Random Fields}

The geotechnical parameter uncertainty of soils may be relevantly reflected by threedimensional random fields. This action requires advanced numerical tools and theoretical background in advanced probabilistic methods. Although random field generation is an advanced issue, implemented in relevant software [11,37], the random field methodology is still rare in real-life engineering applications. The only software of wide present use includes simple generators of random fields to be directly entered as input data into standard FEM software.

In this paper, such a simple computational path is also executed. Dedicated software is used to generate the FE input-ready Gaussian two-dimensional and three-dimensional random fields, and the software is described in detail in [38-40]. The software conducts random variable generation employing a conditional acceptance and rejection concept. A conditional function $f_{s}\left(\mathbf{X}_{u} / \mathbf{X}_{k}\right)$ is applied to directly generate an unknown vector $\mathbf{X}_{u}$, assuming that the field part defined by a vector $\mathbf{X}_{k}$ is already generated and is known:

$$
f_{s}\left(\mathbf{X}_{u} / \mathbf{X}_{k}\right)=\left(\operatorname{det} \mathbf{K}_{c}\right)^{-1 / 2}(2 \pi)^{-m / 2} \exp \left(-0.5\left(\mathbf{X}_{u}-\overline{\mathbf{X}_{c}}\right)^{\mathrm{T}} \mathbf{K}_{c}^{-1}\left(\mathbf{X}_{u}-\overline{\mathbf{X}_{c}}\right)\right)
$$

where $\mathbf{K}_{c}$ is a conditional correlation matrix, $\mathbf{X}_{c}$ is a conditional vector of mean values, and $m$ stands for the dimension of the correlation matrix $\mathbf{K}$.

The most important aspect of random field modelling is the correlation function adoption, dedicated to a given problem. Various correlation function definitions are found in the literature; usually, the function is assumed a priori. Comprehensive studies on parameter determination based on targeted research results can be found (see, e.g., [21]). Random fields of standard engineering materials (e.g., soils, concretes, composites) make use of the exponential correlation function related to the first-order autoregressive function or a Markov process model. In a three-dimensional problem case, it has the following definition [41]:

$$
\rho(x, y)=\rho(x) \rho(y) \rho(z)=\mathrm{e}^{-d_{x}|x|-d_{y}|y|-d_{z}|z|}
$$

where $d_{x}, d_{y}$, and $d_{z}$ are damping parameters describing the correlation decay, and $|x|,|y|$, and $|z|$ are the distances between the points of the random field, along respective axes.

Due to simple engineering interpretation, the correlation function (2) has been used in many cases (see, e.g., [17-19,42]).

In the calculations, diverse random field types were generated, differing in the value of the adopted damping parameter $d \equiv d_{x}=d_{y}=d_{z}\left[\mathrm{~m}^{-1}\right]$. The parameters vary from $d=0.01 \mathrm{~m}^{-1}$ (a relatively large correlation range) through $d=0.1 \mathrm{~m}^{-1}, d=0.2 \mathrm{~m}^{-1}$, and $d=1.0 \mathrm{~m}^{-1}$ to $d=5.0 \mathrm{~m}^{-1}$ (a relatively low correlation range). Figure 2 illustrates the impact of the assumed damping parameter $d_{x}$ on the correlation between the points (finite elements of the subsoil block). 


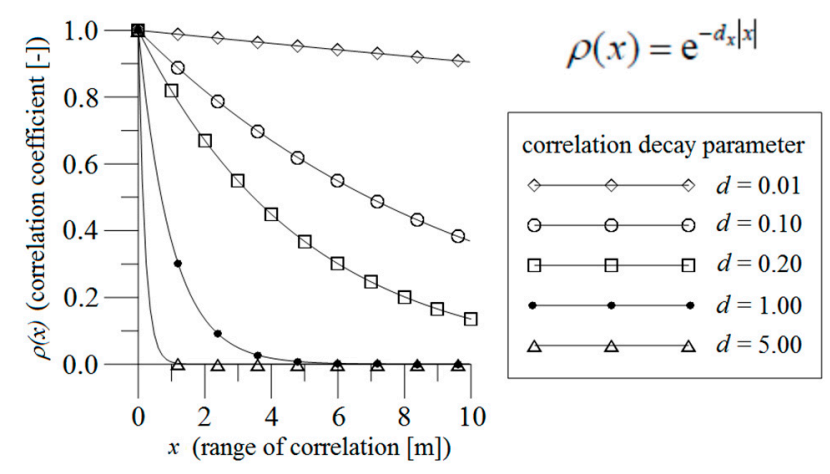

Figure 2. Correlation range for different damping parameters $d$.

The random field applied in the FE model of the subsoil block is based on the previous truncated Gaussian variable of Young's modulus $E\left(\mu_{E}=28,000 \mathrm{kPa}, \sigma_{E}=7000 \mathrm{kPa}, t=4\right)$. A number of 200 three-dimensional Gaussian fields of $n_{r e}=1000$ points are generated, corresponding to each of the five correlation decay parameter values, directly implemented in the FE model. The number is limited to 200 samples only, as the time required to generate the fields, to create FE models incorporating these data, to conduct the numerical calculations, and to analyse the results is extremely significant. A graphical example of a generated highly correlated random field $\left(d=0.01 \mathrm{~m}^{-1}\right)$ is shown in Figure 3.

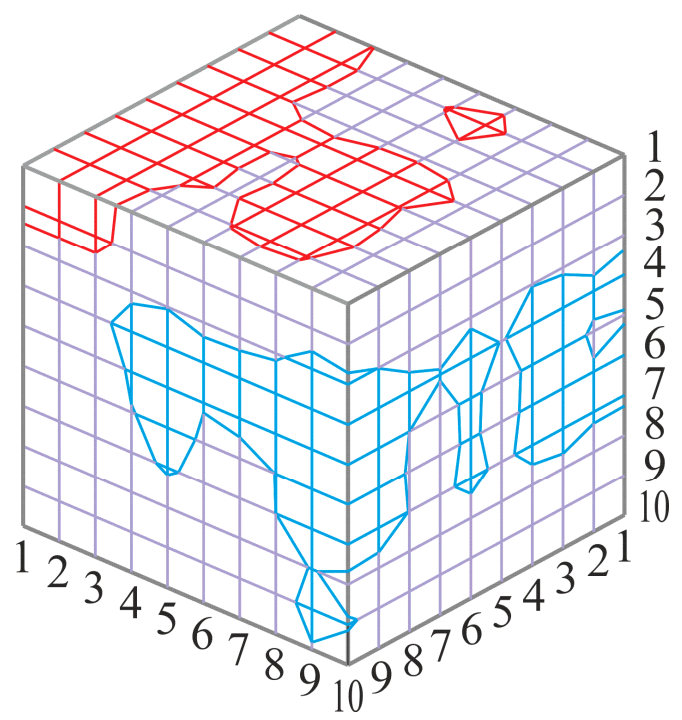

Figure 3. Example of a three-dimensional random field representing Young's modulus; the numbers on respective axes denote node ordinal numeration.

The assessed displacements $\delta_{R F}^{i}(i=1, \ldots, 200)$ of a highly correlated random field $\left(d=0.01 \mathrm{~m}^{-1}\right)$ are shown in Figure 4 , along with the convergence diagrams for both mean value $\mu_{\delta_{\mathrm{RF}}}$ and standard deviation $\sigma_{\delta_{\mathrm{RF}}}$ of model response. The figure detects two positive vertical axes-standard deviation is presented on a positive upward axis, while displacements refer to a positive downward axis, the latter reflecting the settlement direction. This assumption is valid in subsequent similar figures. 


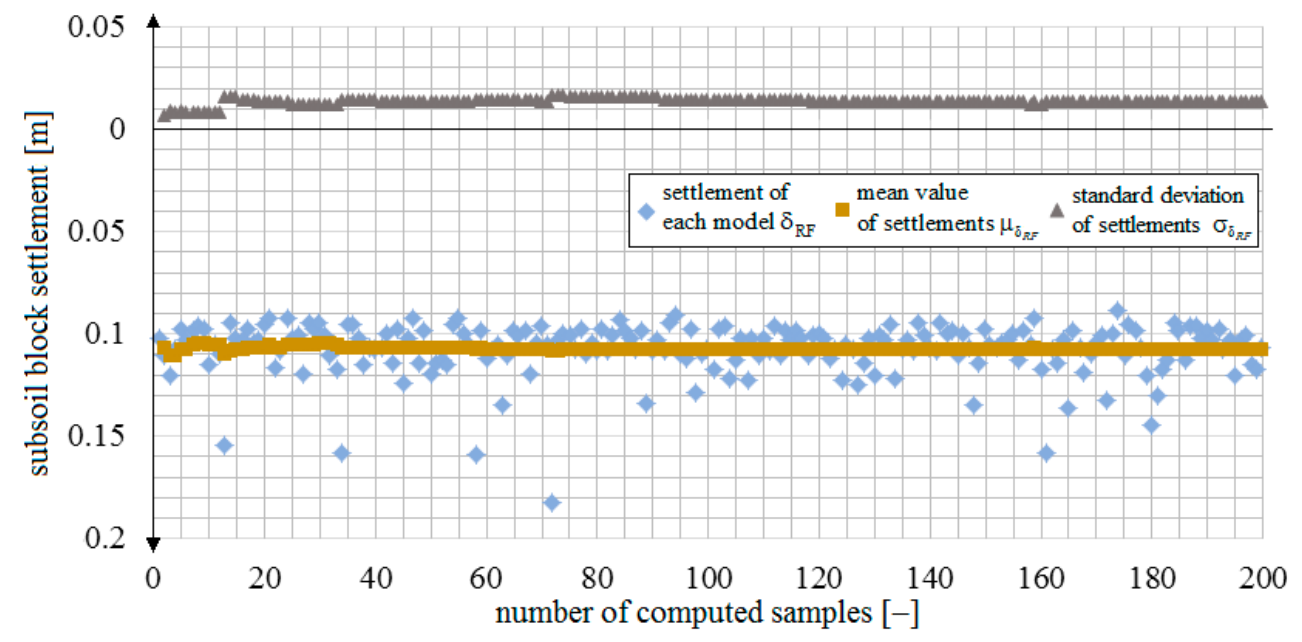

Figure 4. Convergence of simulation-based settlement estimation, the random field model, $d=0.01 \mathrm{~m}^{-1}$.

The data in Figure 4 are representative of all five cases of different correlation decay parameters, due to the similar mechanical response of the soil block in the case of the other four damping parameters $d$. The MC simulation convergence criterion is adopted: convergence holds if the mean value relative error is lower than $\Delta_{\mu}=0.01 \%$ and the standard deviation relative error is lower than $\Delta_{\sigma}=1 \%$ in the course of a 20-sample computation. In all five cases, the adopted criterion was fulfilled. However, higher MC simulation precision requires computing a larger number of samples. Computation of the extreme central node settlements $\delta_{R F}$, their mean values $\mu_{\delta_{\mathrm{RF}}}$, and standard deviations $\sigma_{\delta_{\mathrm{RF}}}$ for all considered FE models are shown in Table 1.

Table 1. Soil block settlement parameters, 200-item simulation procedure, random field approach.

\begin{tabular}{cccc}
\hline $\begin{array}{c}\text { Correlation } \\
\text { Decay Parameter } \\
\boldsymbol{d}\left[\mathbf{m}^{-\mathbf{1}}\right]\end{array}$ & $\begin{array}{c}\text { Mean } \\
\text { Value } \\
\boldsymbol{\mu}_{\boldsymbol{R}_{\mathrm{RF}}}[\mathrm{m}]\end{array}$ & $\begin{array}{c}\text { Standard } \\
\text { Deviation } \\
\sigma_{\delta_{\mathrm{RF}}}[\mathrm{m}]\end{array}$ & $\begin{array}{c}\text { Extreme } \\
\text { Settlement } \\
\boldsymbol{\delta}_{\boldsymbol{R F}}^{\text {extr }}[\mathrm{m}]\end{array}$ \\
\hline 0.01 & 0.1076 & 0.0132 & 0.1825 \\
0.1 & 0.1057 & 0.0066 & 0.1350 \\
0.2 & 0.1050 & 0.0048 & 0.1279 \\
1.0 & 0.1052 & 0.0016 & 0.1109 \\
5.0 & 0.1048 & 0.0009 & 0.1085 \\
\hline
\end{tabular}

Note that Figure 4 displays peaks in the settlement diagram, slightly disturbing the response parameter convergence. In a highly correlated random field $\left(d=0.01 \mathrm{~m}^{-1}\right)$, the extreme value $\delta_{R F}^{d=0.01}=0.1825 \mathrm{~m}$ is reached (Table 1). The peaks stem from the FE models with a low Young's modulus taken as the basis for random field generation. Due to high correlation, an initially low modulus propagates to a significant number of finite elements in the block volume, thus generating a weak subsoil, prone to excessive displacements.

The peaks vanish with correlation decay increase, as the propagation of the initial low modulus quickly fades, not allowing for an extensive material weakening of the FE subsoil model. In a slightly correlated random field $\left(d=5.0 \mathrm{~m}^{-1}\right)$, the peaks are not observable, so the extreme displacement $\delta_{R F}^{d=5.0}=0.1085 \mathrm{~m}$ does not come too far from the mean value estimated: in this case, $\mu_{R F}^{d=5.0}=0.1048 \mathrm{~m}$ (Table 1 ).

The computational results (Table 1) can be summarized as a closed-form relation between the correlation decay parameter and standard deviation variability of the analysed settlement. The logarithmic approximation $\sigma_{\delta_{\mathrm{RF}}}(d)=-0.00201831 \ln (d)+0.00363733$ is shown in Figure 5. As the settlement mean value remains at a specified level throughout the computations of distinct sets (Table 1), it is not considered here. 


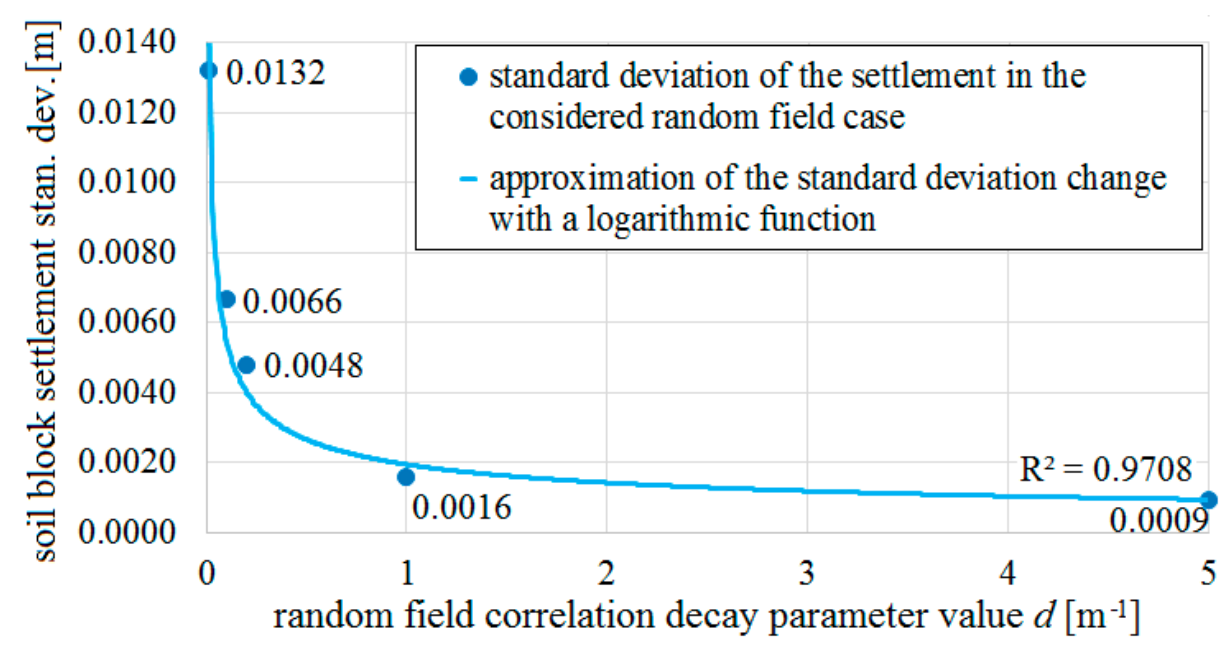

Figure 5. Soil block settlement dispersion versus the correlation decay parameter $d$; random field approach.

Figure 5 shows that the standard deviation change of the settlement in a random field approach to FE models may be represented by appropriate damping parameters $d$ in Equation (2). However, random field generation is difficult to perform and interpret.

The field definition also requires an advanced calibration of the FE model, while the type of correlation function has to be taken in advance with its parameters, e.g., correlation lengths or the damping parameter.

\subsection{The Monte Carlo FE Material Model}

There are obstacles in the application of random fields in engineering problems; hence, an alternative variant is proposed. The generated Young's moduli are linked with specific finite elements of the numerical model. Merging the elements into sub-blocks makes it possible to produce the global subsoil response. A variation of the method results, e.g., foundation settlements, is reflected by a direct Monte Carlo simulation. Thus, the paper proposes a Monte Carlo FE material model to directly represent the uncertain character of the subsoil volume. Parametric analysis of four FE models illustrates the computational course, and the generated Young's moduli are linked with the variable sub-block structure.

\subsubsection{The Homogenous FE Model Described with One Random Variable}

The initial model assigns a single random variable $n_{E}=1$ (with the truncated normal distribution of Young's modulus of the soil: $\mu_{E}=28,000 \mathrm{kPa}, \sigma_{E}=7000 \mathrm{kPa}, t=4$ ) to all $n_{r}=1000$ elements. Thus, the entire block stiffness is represented by a single randomly generated value. Such an FE model is straightforward in its numerical operation; hence, frequently introduced in probabilistic analysis.

The first stage of the analysis checks the convergence of the investigated displacement with $200 \mathrm{FE}$ models computed for different $E_{i}$ random variable generations. The mean value $\mu_{\delta_{1}}^{200}=0.1087 \mathrm{~m}$ and standard deviation $\sigma_{\delta_{1}}^{200}=0.0091 \mathrm{~m}$ are obtained here. In the second stage, the test was expanded to a total of 10,000 samples, bringing a sample mean $\mu_{\delta_{1}}^{1000}=0.1097 \mathrm{~m}$ and standard deviation $\sigma_{\delta_{1}}^{10000}=0.0174 \mathrm{~m}$. The computed displacement of each FE model (sample) $\delta_{1}^{i}$ and convergence of both mean value $\mu_{\delta_{1}}$ and standard deviation $\sigma_{\delta_{1}}$ of the settlement are shown in Figure 6. The 200-sample test is separated in Figure 6a, and the complete 10,000-sample test is presented in Figure 6b. 


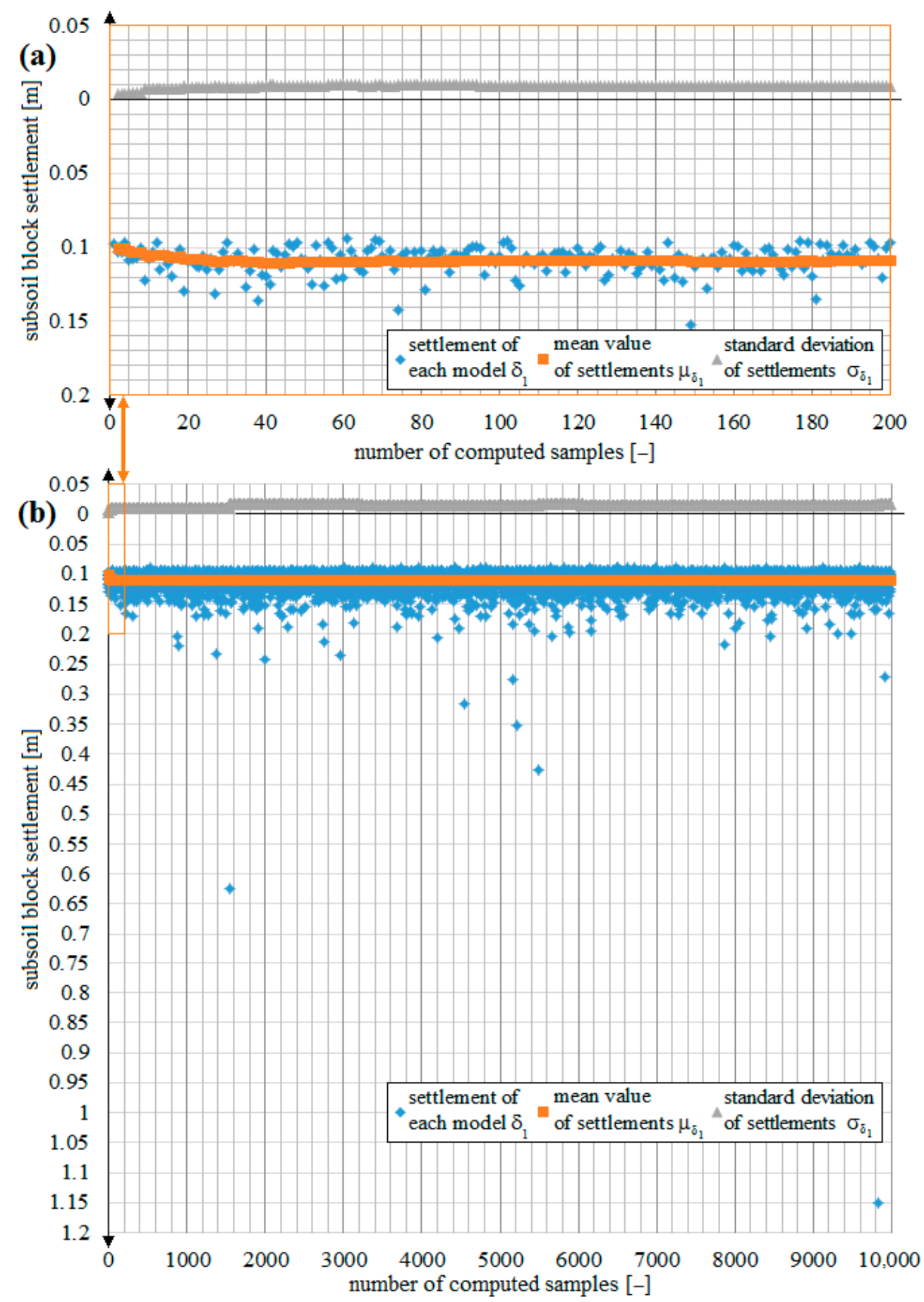

Figure 6. Convergence of simulation-based settlement estimation: (a) the 200-sample test; (b) the 10,000-sample test; the homogeneous FE model, $n_{E}=1$.

The 10,000-sample mean does not substantially differ from the 200-sample test, but the standard deviation does. The latter stems from excessive soil settlements reaching $\delta_{1}^{10000}=1.1505 \mathrm{~m}$ (the 9851st sample) which, in turn, is produced by extremely low Young's moduli generated for the FE models. The highest settlement in the initial domain of 200 samples is $\delta_{1}^{200}=0.1525 \mathrm{~m}$ (the 149th sample). The computed peaks exceed the settlement allowable for the ZSoil ${ }^{\circledR}$ nonlinear material model. The excessive cases should be analysed separately in terms of the large displacement theory. It should be stated that the single random variable solution (Young's modulus) for all finite elements is wrong. 
If a homogeneous FE soil model is incorporated, the dispersion is unclear. The dispersion decreases with a lower truncation parameter of Young's modulus distribution, e.g., $t=1.0$; however, such an assumption is not justified by in situ soil studies. Soils in their natural state show significant variability, and the coefficient of variation may reach 0.4 (see [43-45]). Thus, larger values of the truncation parameter are recommended $(t \gg 1.0)$.

Although the presented results (Figure 6a, 200 samples) are improper and only accidentally reliable (no possible peaks are observable), they serve as a reference point for further analysis.

\subsubsection{The FE Models Described with Several Uncorrelated Random Variables}

An alternative variant of the FE model is proposed to produce results of higher numerical quality. The model introduces a specified, relatively small number of random Young's moduli, assigned to smaller subsets of adjacent elements of the entire soil block.

First, a subdivision of the analysed subsoil block of $n_{r}=1000$ elements into eight equal sub-blocks was assumed $\left(n_{E}=8\right)$, as presented in Figure 7 .

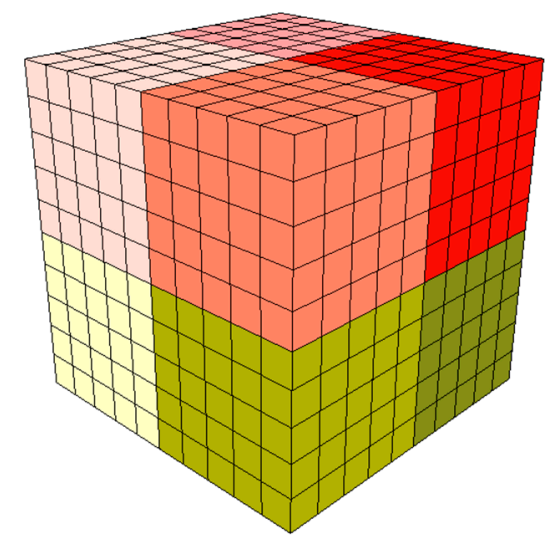

Figure 7. The subsoil FE model; 8 distinct sub-blocks of $E$ modulus, $n_{E}=8$.

As a result, each sub-block consists of $5 \times 5 \times 5=125$ elements. For each sub-block, a distinct random Young's modulus $E$ is independently generated; in turn, the FE model is described by $1000 / 125=8$ different Young's moduli. The analysis is limited to $200 \mathrm{FE}$ models only. Satisfactory convergence of the solution is reached under the conditions of $\Delta_{\mu}$, and $\Delta_{\sigma}$ is set in the random field case (Figure 8).

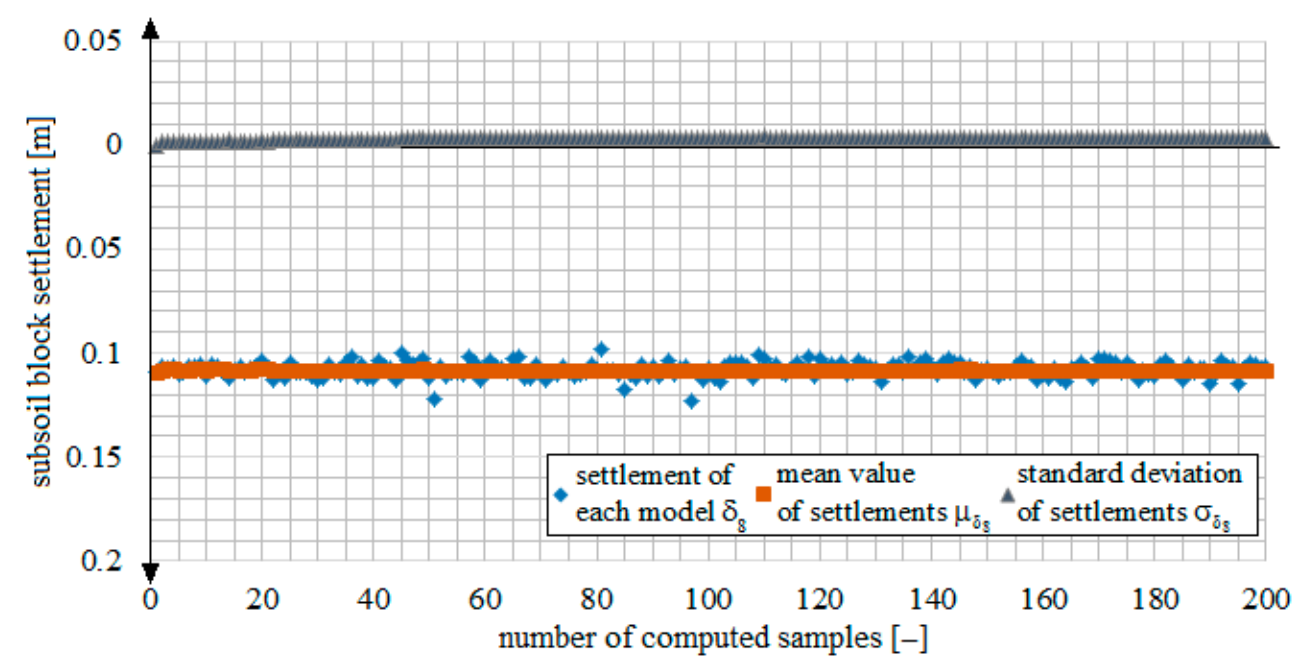

Figure 8. Convergence of simulation-based settlement estimation; the Monte Carlo FE material model, $n_{E}=8$. 
Mean value and the standard deviation of the soil settlement are $\mu_{\delta_{8}}^{200}=0.1079 \mathrm{~m}$ and $\sigma_{\delta_{8}}^{200}=0.0036 \mathrm{~m}$, respectively. An extreme displacement $\delta_{8}^{200}=0.1233 \mathrm{~m}$ was reached. Similar to the homogeneous subsoil block, the unjustified central node displacement peaks may also appear, following a large number of samples. However, contrary to the single variable model, the peaks occur only when small Young's moduli are generated for the majority of eight sub-blocks, and the probability of such a generation seems relatively low.

To further refine the analysis, another subdivision of the analysed subsoil block is introduced. Here, the 1000-element block is divided into 125 equal sub-blocks (Figure 9), each consisting of $2 \times 2 \times 2=8$ elements. This means an input of $1000 / 8=125$ different Young's moduli into the global FE model $\left(n_{E}=125\right)$.

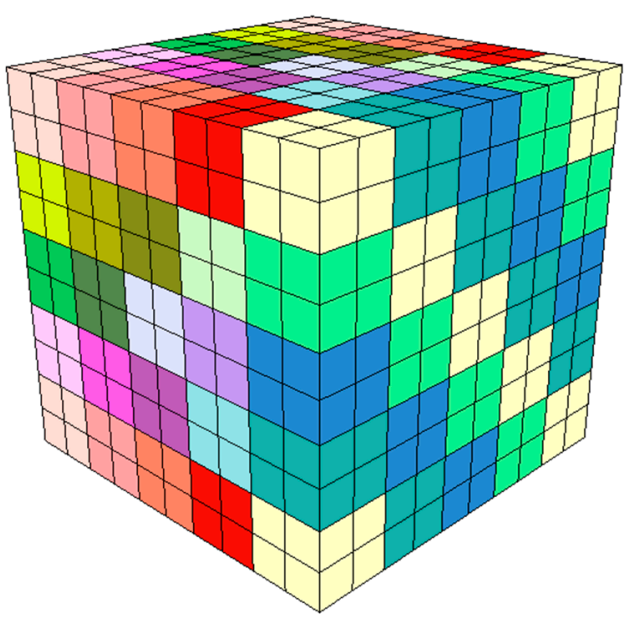

Figure 9. The subsoil FE model; 125 distinct sub-blocks of $E$ modulus, $n_{E}=125$.

At first, based on $200 \mathrm{FE}$ model samples, mean value $\mu_{\delta_{125}}^{200}=0.1083 \mathrm{~m}$ and standard deviation $\sigma_{\delta_{125}}^{200}=0.0024 \mathrm{~m}$ were estimated. An extreme displacement $\delta_{125}^{200}=0.1165 \mathrm{~m}$ occurs. The solution presented in Figure 10 features a small scatter in individual values of central node displacements.

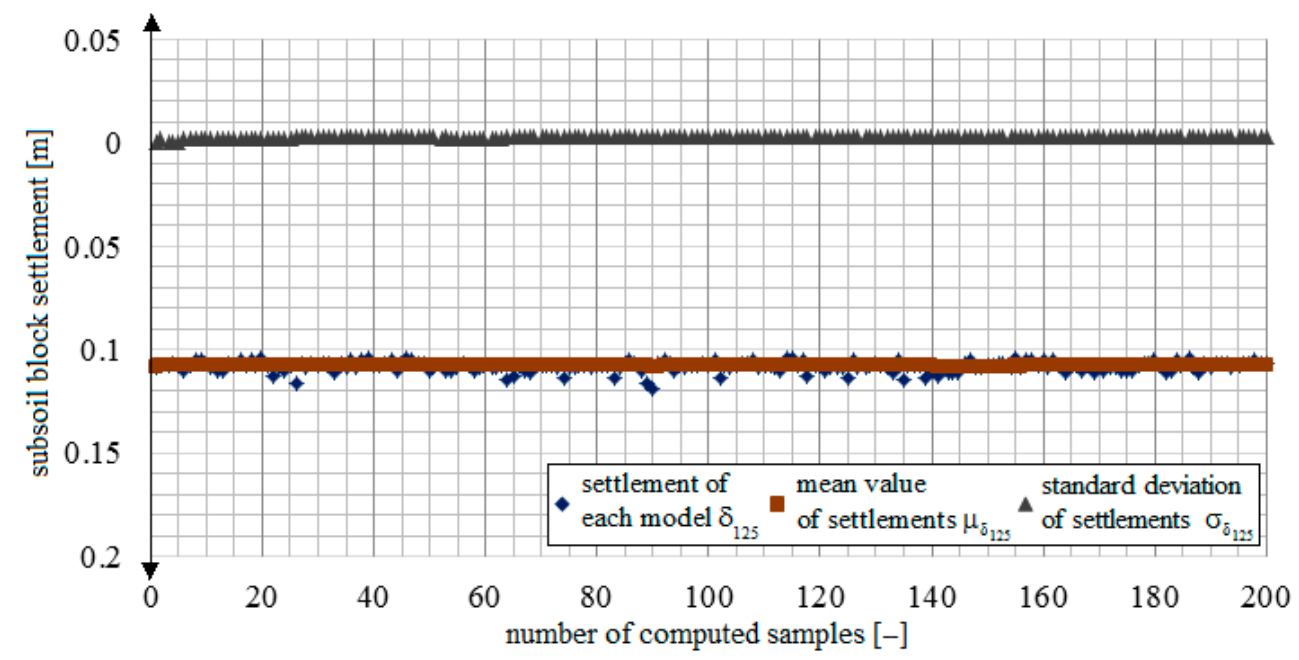

Figure 10. Convergence of simulation-based settlement estimation; the Monte Carlo FE material model; 200 samples, $n_{E}=125$.

Although convergence holds for $200 \mathrm{MC}$ samples, under the previous conditions, a broader scale analysis of 10,000 FE models is performed. The results and convergence of the crucial parameters of the random response are shown in Figure 11. 


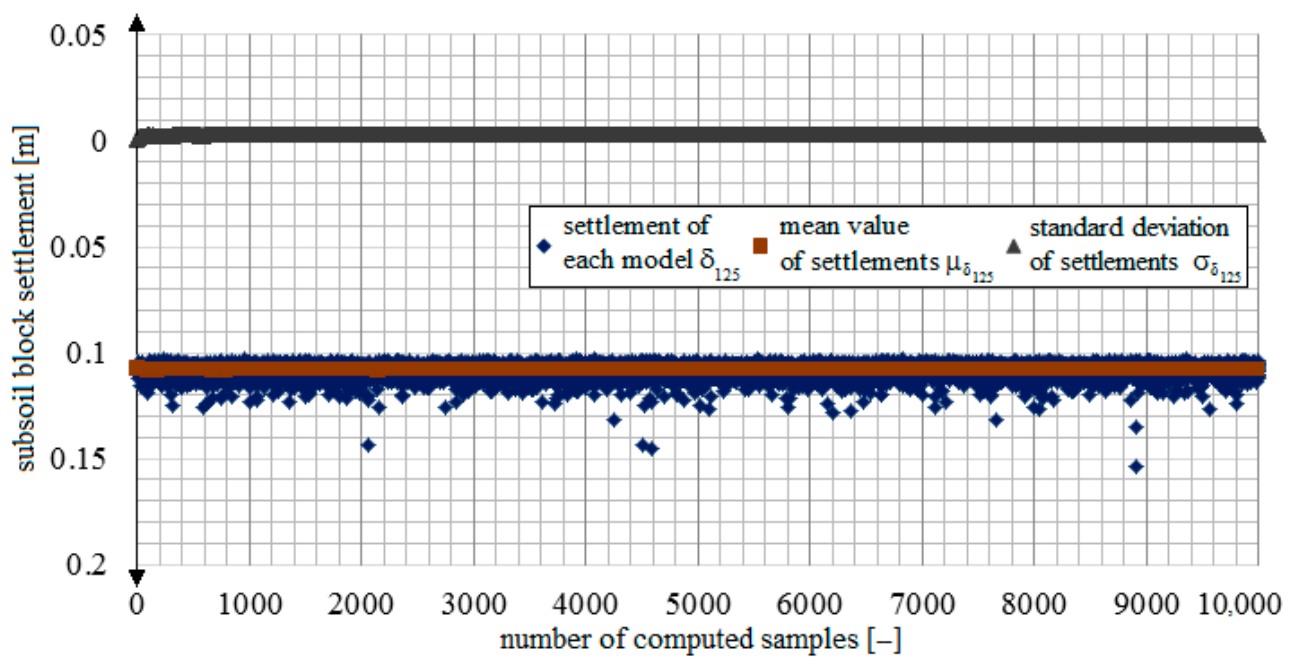

Figure 11. Convergence of simulation-based settlement estimation; the Monte Carlo FE material model; 10,000 samples, $n_{E}=125$.

According to prior predictions, solutions arrive in the 10,000-sample computations with relatively large settlements $\left(\delta_{125}^{10000}=0.1539 \mathrm{~m}\right)$. Contrary to the single variable $10,000 \mathrm{FE}$ model analysis (Figure $6 \mathrm{~b}$ ), the peaks do not disturb solution convergence, the mean value here $\mu_{\delta_{125}}^{10000}=0.1083 \mathrm{~m}$ is identical to the $200 \mathrm{FE}$ sample case $\left(\mu_{\delta_{125}}^{200}=0.1083 \mathrm{~m}\right)$, and the standard deviation $\sigma_{\delta_{125}}^{10000}=0.0029 \mathrm{~m}$ differs slightly from the $\sigma_{\delta_{125}}^{200}=0.0024 \mathrm{~m}$ result.

Finally, an FE model is assembled, where each of 1000 elements is given a unique, random Young's modulus $\left(n_{E}=1000\right)$. Although a white noise-like modulus distribution does not properly characterize the soil medium (opposite to the homogeneous description), the calculations are performed to check if the FE model subdivision into smaller subvolumes affects its computed response. A series of 200 samples is analysed, and the mean value $\mu_{\delta_{1000}}^{200}=0.1075 \mathrm{~m}$ and standard deviation $\sigma_{\delta_{1000}}^{200}=0.0005 \mathrm{~m}$ are obtained. The extreme displacement $\delta_{1000}^{200}=0.1105 \mathrm{~m}$ is reached, similar to the 200-sample calculation of the 125 variable case $\left(\delta_{125}^{200}=0.1165 \mathrm{~m}\right)$. The results and convergence of both random parameters are illustrated in Figure 12.

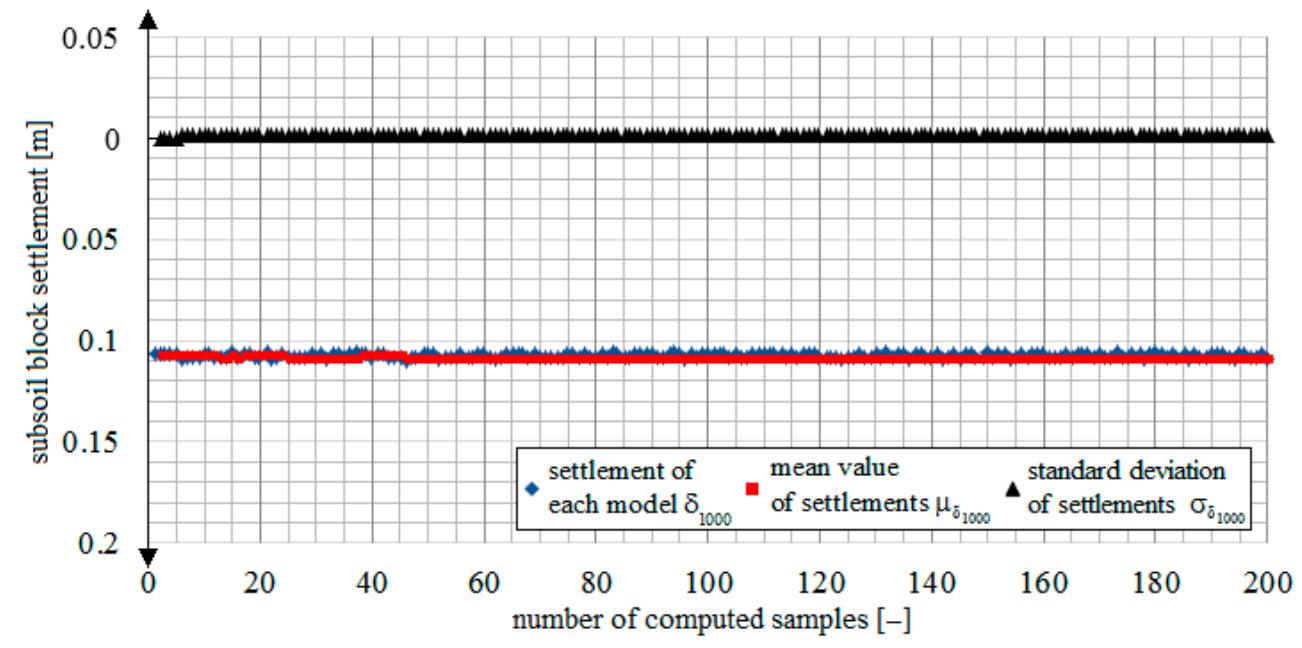

Figure 12. Convergence of simulation-based settlement estimation; the Monte Carlo FE material model; 200 samples, $n_{E}=1000$. 
Summing up, all essential results of the considered computational cases (Young's moduli modelled by sets of random variates) are presented in Table 2. With regard to FE models, the mean settlement is not affected by Young's modulus variation, but the standard deviation of the central node settlement decreases with the random variable domain rise. The extreme settlements are also listed in Table 2. It should be noted that if different sample sets are computed, the presented output is about to vary. This is due to extreme deflections since a larger number of analysed samples increases the probability of unrealistic settlement peaks occurrence.

Table 2. Soil block settlement parameters, the 200 -item and the 10,000-item simulation procedure, and the Monte Carlo FE material model.

\begin{tabular}{|c|c|c|c|c|c|c|}
\hline \multirow[b]{2}{*}{$n_{E}$} & \multicolumn{3}{|c|}{200 FE Models Incorporated } & \multicolumn{3}{|c|}{ 10,000 FE Models Incorporated } \\
\hline & $\begin{array}{c}\text { Mean } \\
\text { Value } \\
\mu_{\delta_{n_{E}}}[\mathrm{~m}]\end{array}$ & $\begin{array}{c}\text { Standard } \\
\text { Deviation } \\
\sigma_{\delta_{n_{E}}}[\mathrm{~m}] \\
\end{array}$ & $\begin{array}{c}\text { Extreme } \\
\text { Settlement } \\
\delta_{n_{E}}^{\text {extr }}[\mathrm{m}]\end{array}$ & $\begin{array}{c}\text { Mean } \\
\text { Value } \\
\mu_{\delta_{n_{E}}}[\mathrm{~m}]\end{array}$ & $\begin{array}{c}\text { Standard } \\
\text { Deviation } \\
\sigma_{\delta_{n_{E}}}[\mathrm{~m}] \\
\end{array}$ & $\begin{array}{c}\text { Extreme } \\
\text { Settlement } \\
\delta_{n_{E}}^{\text {extr }}[\mathrm{m}] \\
\end{array}$ \\
\hline 1 & 0.1087 & 0.0091 & 0.1525 & 0.1097 & 0.0174 & 1.1505 \\
\hline 8 & 0.1079 & 0.0036 & 0.1233 & \multicolumn{3}{|c|}{ calculations not performed } \\
\hline 125 & 0.1083 & 0.0024 & 0.1165 & 0.1083 & 0.0029 & 0.1535 \\
\hline 1000 & 0.1075 & 0.0005 & 0.1105 & \multicolumn{3}{|c|}{ calculations not performed } \\
\hline
\end{tabular}

Similar to random field modelling, an approximation of settlement standard deviation versus the number of the assumed random Young's modulus variables is performed (Figure 13). An assumption is made on the horizontal axis-a cubic root of the number of variables $c_{E}=\sqrt[3]{n_{E}}\left(0<c_{E}<10\right)$ is adopted, not the direct number $n_{E}\left(0<n_{E}<1000\right)$. The logarithmic function is approximated $\sigma_{\delta_{n_{E}}}=-0.00339796 \ln \left(c_{E}\right)+0.00783447$ (see Figure 13). Note that the diagram resembles the one in Figure 5 in the analysis of FE models with the random field modelling of Young's modulus $E$.

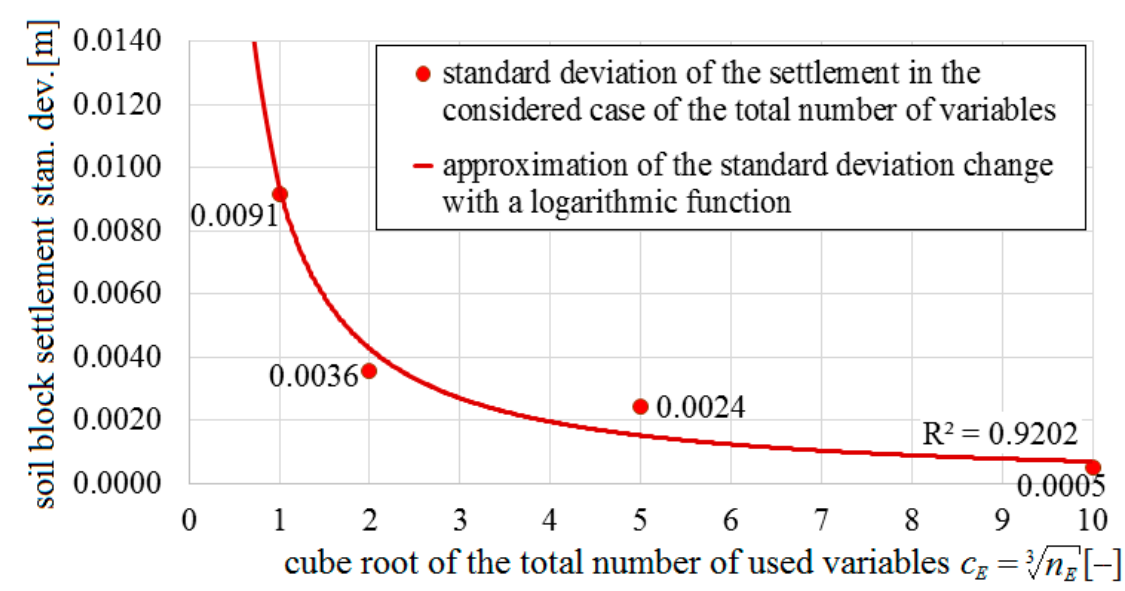

Figure 13. Soil block settlement dispersion versus the cubic root of the number of random variables $c_{E}=\sqrt[3]{n_{E}}$.

The similarity between the diagrams in Figures 5 and 13 is not accidental. An apparent relationship is observable between the random field regions with similar stiffness moduli $E$ defined by the correlation decay parameter $d$ (Figure 3 ) and the number of sub-blocks $n_{E}$ that divide the entire FE model volume according to a given mode (Figure 9). Although it is impossible to analytically define these relationships, they are visible in terms of extreme case analysis. When defining the total block volume by a single random value $\left(n_{E}=1\right)$, ideal homogenization of the material emerges, and it resembles the random field with infinitely strong correlation, $d \rightarrow 0$. Both simulations imply a large result scatter and significant standard deviation of the investigated settlement. While the number of sub- 
blocks is equal to the number of finite elements $\left(n_{E}=1000\right)$, the FE model resembles the white noise random field of extremely weak correlation $(d \gg 5)$. It is evident that the cases corresponding to the real-life soil conditions are included between these extremes. Since random field computations are difficult, they can be represented by accurate block division into sub-volumes of single Young's moduli.

Note that the determined logarithmic approximations (Figures 5 and 13) can be related to the soil model presented in the paper only. However, it is supposed that the observed relation can be estimated in any other FE model of a geotechnical structure resting on random subsoil or the FE models of slopes of a complex multi-layered geological structure with uncertain parameters, e.g., prone to stability loss.

The optimal number of singular variables to be randomly generated in a simple approach $n_{E}$ can be devised. The data collected in Figure 13 lead to an assumption that the refined FE model with $n_{E}=125$ variables may be regarded as the finest one. If $n_{E}=8$ is assumed, the generated FE model becomes too similar to a model defined by a homogeneous field. The results show unjustified large jumps, so to reach the convergence of the MC solution, too many samples are required, discarding the analysis from real-life engineering problems. For $n_{E}=125$, the results are practically independent of the number of FE models applied in the computational series, and the result scatter is realistic. It balances the complexity of model generation and output reliability well. Nevertheless, accepting $n_{E}=125$ is arbitrary and strongly related to the analysed case. However, the diagram in Figure 13 shows that for such a value, the variability range of FE model parameters is small enough to produce engineering-sound solutions, decisive when investigating real-life problems.

In a general case, for any FE model, the number of sub-blocks with the same material parameters $n_{E}$ should be specified. The easiest way to define this number is based on the percentage of the number of sub-blocks $p_{E}\left(0.0<p_{E}<1.0\right)$ to the total number of the finite elements in the model $n_{e l}$ :

$$
n_{E}=p_{E} \cdot n_{e l}
$$

For example, in the considered FE model of the block involving $n_{e l}=1000$ finite elements, the optimal number of different random values generated for the task should be $n_{E}=0.125 \cdot 1000=125\left(p_{E}=0.125\right)$. In turn, the entire volume is divided into $125 \mathrm{sub}$ blocks, each including 1000/125 = 8 finite elements. In the case of an irregular mesh of finite elements, specific random variables are linked with relevant volumes to represent their contribution to the entire modelled structure. Such computations, however, require additional, pre-generated external procedures assigning a certain number of Young's moduli to precisely set sub-volumes, matching the FE model syntax. A regular mesh of finite elements, usually applicable in subsoil models, corresponds to the presented approach.

Unfortunately, no clear distinction arises on the FE model definition, and the model adoption is intuitive. Despite this, such a simplified random variable approach is dedicated to advanced geotechnical engineering design to replace the three-dimensional random field analysis.

\section{FE Model of a Continuous Strip Foundation}

The advanced computational three-dimensional FE model of a perfectly continuous foundation resting on a three-dimensional random subsoil verifies the prior FE solution of a subsoil block. A sufficiently long segment of the foundation is analysed to provide numerical results of a displacement of the central node of the foundation longitudinal cross-section free of any interference of the boundary elements. The considered FE model of a segment of the strip footing foundation of dimensions $2.0 \times 0.5 \times 20.0[\mathrm{~m}]$, resting on a spatially random subsoil, is presented in Figure 14. A volume of $18.0 \times 6.0 \times 6.0$ [m] is generated in the ZSoil ${ }^{\circledR}$ software, and the outer elements are properly constrained to accurately reflect the mechanical response of the entire subsoil under the foundation. The subsoil under the foundation level is only modelled, and the soil layers lying above the foundation-subsoil interface are replaced by a uniformly distributed load $q=18.0 \mathrm{kPa}$ situated on the upper surface of the subsoil FE model. The dead load of the foundation wall 
is represented by a linear load $P=1.0 \mathrm{MN}$ per FE length. The wall-foundation connection makes the deflections compatible; the rotations do not follow the rule.

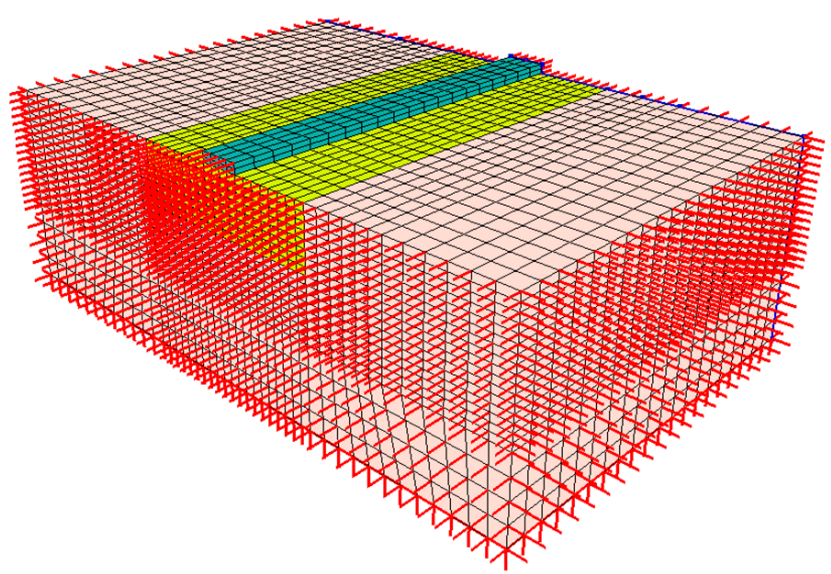

Figure 14. The FE model of a strip foundation resting on a three-dimensional random subsoil.

Probabilistic analysis requires multiple repetitions of similar computations; it is a significantly time-consuming process, so assuming an optimal refinement of the finite element mesh is necessary. Division of the subsoil into a given number of elements should ensure the desired result accuracy, also providing a relatively short calculation time of a single case. Therefore, the subsoil volume under the foundation is divided into several sub-volumes, variable in the degree of finite element mesh condensation (Figure 14). Moreover, the approach to the subsoil volume definition is also diverse, as the subsoil volume $(10.0 \times 6.0 \times 6.0[\mathrm{~m}])$ directly under the strip foundation is assumed random (marked in yellow in Figure 14), while the remaining volume is modelled deterministic (marked in pink in Figure 14). To facilitate the description of the random soil sub-volume with random fields, a regular mesh of three-dimensional continual eight-node elements (Q4 continuum 2D) with dimensions $0.5 \times 0.75 \times 0.75[\mathrm{~m}]$ is adopted. This brings a total number of 3200 finite elements to constitute the random sub-volume.

In the random sub-volume of the soil, Young's modulus parameters are assumed the same as in the case of a soil cube (Chapter 2). In the deterministic part, the parameter was set to its mean value $E=\mu_{E}=28 \mathrm{MPa}$.

The concrete of the foundation is considered elastic, and its parameters correspond to the $\mathrm{C} 30 / 37$ concrete (with Young's modulus of $E=33 \mathrm{GPa}$ ).

The soil block analysis shows an optimal finite element domain of diverse Young's moduli equal to $12.5 \%$ ( $p_{E}=0.125$, Equation (3)) of the total FE domain. Here, the Monte Carlo results converge fast, and their dispersion is moderate. The random domain of the strip foundation subsoil model (3200 elements, Figure 14) is split into 400 smaller subvolumes, each of them made of eight finite elements $(400 / 3200 \cdot 100 \%=12.5 \%)$. While this generated random variable is applied to each sub-volume, 400 separate Young's modulus random variables are incorporated in a single model, $n_{E}=400$.

The computations are performed for 200 generated foundation models. To assess solution convergence, parameter variation is examined on the central point settlement of the foundation, neglecting the boundary condition impact (Figure 15). Based on the computations, variable settlement shows its mean value $\mu_{\delta_{400}}^{\text {strip }}=0.0976 \mathrm{~m}$ and standard deviation $\sigma_{\delta_{400}}^{\text {strip }}=0.0017 \mathrm{~m}$. 


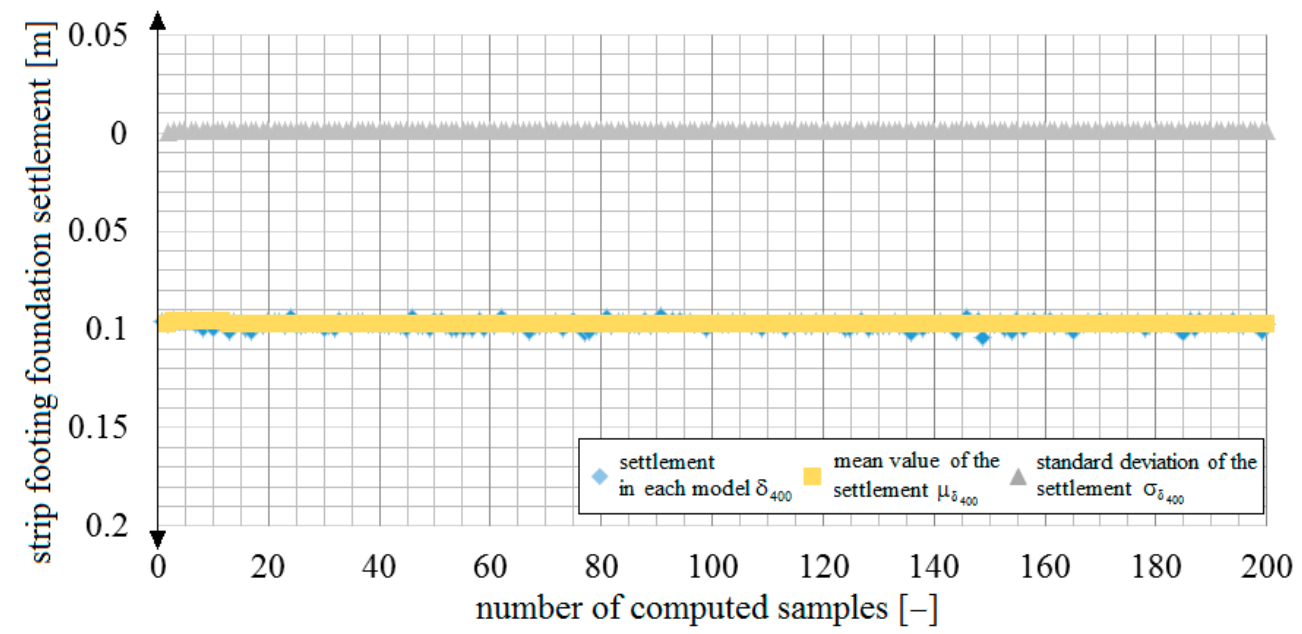

Figure 15. Convergence of simulation-based strip foundation settlement estimation, $n_{E}=400$.

Figure 16 shows selected settlement cases along the foundation central axis.

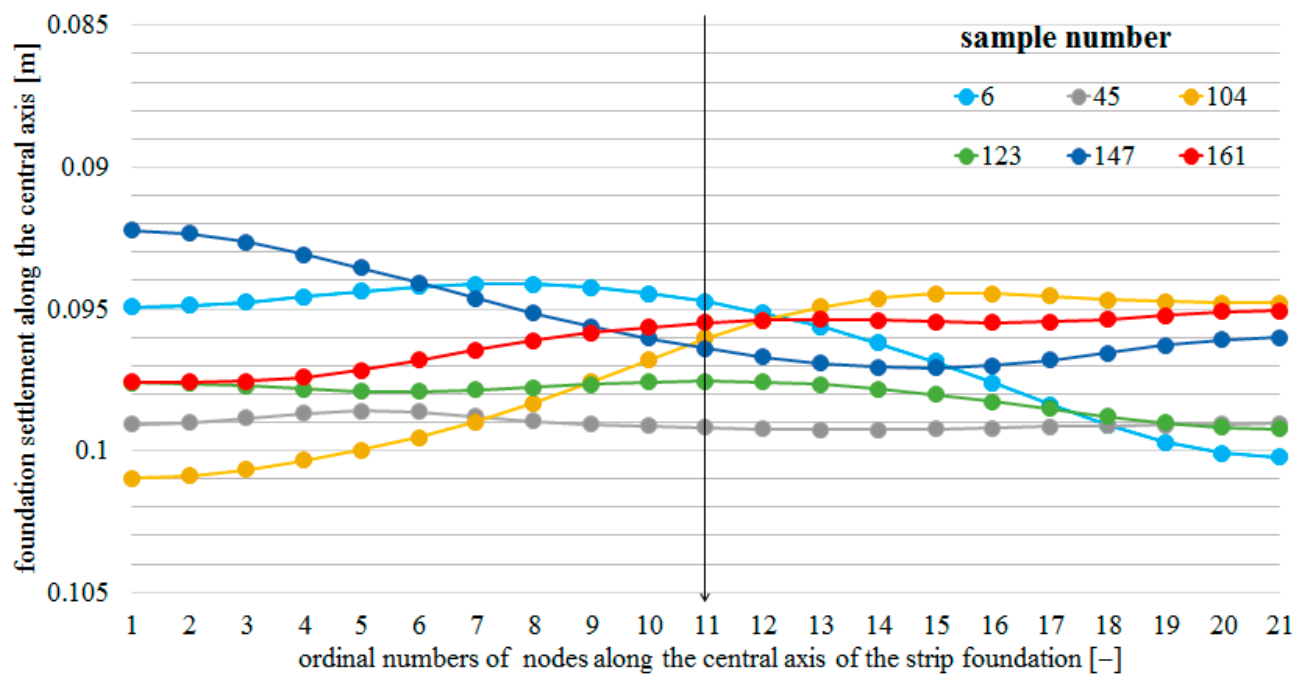

Figure 16. Several examples of the strip foundation settlement, $n_{E}=400$.

To provide a comparison, two additional computational series are conducted: with 50 models where the entire type 1 volume is defined by a single Young's modulus variable (full homogenization) and 50 models where 3200 variables are used (white noise-like simulation). The computational results are shown in Table 3.

Table 3. Strip foundation settlement parameters; the Monte Carlo FE material model.

\begin{tabular}{ccccc}
\hline $\begin{array}{c}\text { Number of } \\
\text { Different Young } \\
\text { Moduli } \boldsymbol{n}_{\boldsymbol{E}}\end{array}$ & $\begin{array}{c}\text { Number of } \\
\text { Simulations }\end{array}$ & $\begin{array}{c}\text { Mean } \\
\text { Value } \\
\mu_{\delta}[\mathrm{m}]\end{array}$ & $\begin{array}{c}\text { Standard } \\
\text { Deviation } \\
\sigma_{\delta}[\mathrm{m}]\end{array}$ & $\begin{array}{c}\text { Extreme } \\
\text { Settlement } \\
\delta_{\text {extr }}[\mathrm{m}]\end{array}$ \\
\hline 1 & 50 & 0.1193 & 0.0103 & 0.1478 \\
400 & 200 & 0.0976 & 0.0017 & 0.1044 \\
3200 & 50 & 0.0943 & 0.0001 & 0.0946 \\
\hline
\end{tabular}

The presented results show that all the conclusions drawn for the initial subsoil block model, presented in Chapter 2, are confirmed. The extreme-value simulations for $n_{E}=1$ and $n_{E}=3200$ form an envelope of the possible task solutions. If the number of variables to capture subsoil uncertainty is chosen according to Equation (3), numerical results obtained 
by the FE model (computed settlements, their mean value, and standard deviation) are more reliable from the engineering viewpoint. Moreover, balance is achieved between modelling accuracy of the subsoil-foundation system, the total time cost of numerical computations, and the quality of the output data.

\section{Conclusions}

Based on the probabilistic analysis presented in the paper, the following remarks and conclusions are made:

- The proposed Monte Carlo simulation-based material variability definition of an FE model allows for an alternative advanced analysis, competitive with the use of three-dimensional random fields;

- There is a possibility to create specific FE models with a relatively regular FE mesh to directly implement the randomly generated data from simple pre-generated external procedures, supporting the presented approach;

- It is optimal to sub-divide the subsoil domain into smaller sub-volumes and to sequentially represent them by unique, independently generated random geotechnical parameters;

- Although the subsoil parameters are assumed identical Gaussian variables (the same $\mu_{E}$ and $\sigma_{E}$ are used to generate their parameters in subsequent computations), the global variability description of the FE model is defined the other way: it significantly affects the standard deviation scatter of the foundation settlement, while the mean values are unchanged;

- From an engineering standpoint, a high result scatter in probabilistic settlement response is unacceptable; thus, modelling the entire random subsoil by a single variable (even with its parameters supported by real-life surveys) is improper;

- Unjustified result dispersion may be reduced, e.g., by introducing truncated (bounded) input variables; however, it is contrary to the natural high variability of soil parameters, displayed by real-life in situ measurements;

- The proposed number of unique random geotechnical parameters is about $12.5 \%$ of the total number of FE elements of the model to balance modelling accuracy with the numerical quality of the solutions;

- The method to assign material parameters to finite elements is considered general, and it allows covering subsoil parameters other than Young's modulus, e.g., yield parameters, cohesion, internal friction angles, and porosity; however, to analyse the impact of all decisive parameters of the adopted soil model, an appropriate parametric analysis should be provided.

This paper finds it advantageous to incorporate relatively simple and regular FE models, with their randomness attributed to a set of randomly generated parameters assigned to adjacent finite elements. An approximate optimal ratio of these parameters to the total number of finite elements is proposed. Hence, simplified, engineer-oriented modelling produces computationally efficient, engineering-sound solutions.

Author Contributions: Conceptualization, J.G.; methodology, K.Ż., K.W., and J.G.; software, K.Ż.; validation, K.Ż. and K.W.; formal analysis, K.Ż.; investigation, K.Ż. and K.W.; resources, K.Ż. and K.W.; data curation, K.Ż. and K.W.; writing-original draft preparation, K.W.; writing-review and editing, K.W.; visualization, K.Ż. and K.W.; supervision, K.W.; project administration, J.G.; funding acquisition, K.W. and J.G. All authors have read and agreed to the published version of the manuscript.

Funding: The APC was funded by the Faculty of Civil and Environmental Engineering, Gdańsk University of Technology, Narutowicza 11/12, Gdańsk 80-233, Poland.

Institutional Review Board Statement: Not applicable.

Informed Consent Statement: Not applicable.

Data Availability Statement: Data available on request from the corresponding author. 
Conflicts of Interest: The authors declare no conflict of interest.

\section{References}

1. Low, B.K.; Phoon, K.K. Reliability-based design and its complementary role to Eurocode 7 design approach. Comput. Geotech. 2015, 65, 30-44. [CrossRef]

2. Phoon, K.K.; Retief, J.V.; Ching, J.; Dithinde, M.; Schweckendiek, T.; Wang, Y.; Zhang, L.M. Some observations on ISO2394:2015 Annex D (Reliability of Geotechnical Structures). Struct. Saf. 2016, 62, 24-33. [CrossRef]

3. Onisiphorou, C. Reliability analysis of bearing capacity for shallow foundations based on Eurocode 7. In Proceedings of the 3rd International Symposium on Geotechnical Safety and Risk, Munich, Germany, 2-3 June 2011; pp. 463-469.

4. Aldosary, M.; Wang, J.; Li, C. Structural reliability and stochastic finite element methods: State-of-the-art review and evidencebased comparison. Eng. Comput. 2018, 35, 2165-2214. [CrossRef]

5. Dilip, D.M.; Sivakumar Babu, G.L. Influence of spatial variability on pavement responses using latin hypercube sampling on two-dimensional random fields. J. Mater. Civ. Eng. 2014, 26, 04014083. [CrossRef]

6. Peng, X.; Li, D.Q.; Cao, Z.J.; Gong, W.; Juang, C.H. Reliability-based robust geotechnical design using Monte Carlo simulation. Bull. Eng. Geol. Environ. 2017, 76, 1217-1227. [CrossRef]

7. Low, B.K. FORM, SORM, and spatial modeling in geotechnical engineering. Struct. Saf. 2014, 49, 56-64. [CrossRef]

8. Beer, M.; Zhang, Y.; Quek, S.T.; Phoon, K.K. Reliability analysis with scarce information: Comparing alternative approaches in a geotechnical engineering context. Struct. Saf. 2013, 41, 1-10. [CrossRef]

9. Phoon, K.K.; Tang, C. Characterisation of geotechnical model uncertainty. Georisk 2019, 13, 101-130. [CrossRef]

10. Fenton, G.A.; Griffiths, D.V. Probabilistic foundation settlement on spatially random soil. J. Geotech. Geoenviron. Eng. 2002, 128, 381-390. [CrossRef]

11. Fenton, G.A.; Griffiths, D.V. Three-dimensional probabilistic foundation settlement. J. Geotech. Geoenviron. Eng. 2005, 131, 232-239. [CrossRef]

12. Puła, W.; Chwała, M. Random bearing capacity evaluation of shallow foundations for asymmetrical failure mechanisms with spatial averaging and inclusion of soil self-weight. Comput. Geotech. 2018, 101, 176-195. [CrossRef]

13. Kasama, K.; Whittle, A.J. Bearing capacity of spatially random cohesive soil using numerical limit analyses. J. Geotech. Geoenviron. Eng. 2011, 137, 989-996. [CrossRef]

14. Ahmed, A.; Soubra, A.H. Probabilistic analysis of strip footings resting on a spatially random soil using subset simulation approach. Georisk 2012, 6, 188-201. [CrossRef]

15. Puła, W.; Zaskórski, Ł. Estimation of the probability distribution of the random bearing capacity of cohesionless soil using the random finite element method. Struct. Infrastruct. Eng. 2015, 11, 707-720. [CrossRef]

16. Al-Bittar, T.; Soubra, A.H. Bearing capacity of strip footings on spatially random soils using sparse polynomial chaos expansion. Int. J. Numer. Anal. Methods Geomech. 2013, 37, 2039-2060. [CrossRef]

17. Drakos, S.; Pande, G.N. Stochastic finite element analysis using polynomial chaos. Stud. Geotech. Mech. 2016, 38, 33-43. [CrossRef]

18. Al-Bittar, T.; Soubra, A.-H.; Thajeel, J. Kriging-based reliability analysis of strip footings resting on spatially varying soils. J. Geotech. Geoenviron. Eng. 2018, 144, 04018071. [CrossRef]

19. Ali, A.; Lyamin, A.V.; Huang, J.; Li, J.H.; Cassidy, M.J.; Sloan, S.W. Probabilistic stability assessment using adaptive limit analysis and random fields. Acta Geotech. 2017, 12, 937-948. [CrossRef]

20. Ahmadabadi, M.; Poisel, R. Assessment of the application of point estimate methods in the probabilistic stability analysis of slopes. Comput. Geotech. 2015, 69, 540-550. [CrossRef]

21. Suchomel, R.; Mašín, D. Probabilistic analyses of a strip footing on horizontally stratified sandy deposit using advanced constitutive model. Comput. Geotech. 2011, 38, 363-374. [CrossRef]

22. Jiang, S.-H.; Huang, J.; Huang, F.; Yang, J.; Yao, C.; Zhou, C.-B. Modelling of spatial variability of soil undrained shear strength by conditional random fields for slope reliability analysis. Appl. Math. Model. 2018, 63, 374-389. [CrossRef]

23. Vessia, G.; Russo, S. Random field theory to interpret the spatial variability of lacustrine soils. Biosyst. Eng. 2018, 168, 4-13. [CrossRef]

24. Chen, L.; Yang, Y.; Zheng, H. Numerical study of soil-rock mixture: Generation of random aggregate structure. Sci. China Technol. Sci. 2018, 61, 359-369. [CrossRef]

25. Xu, W.; Zhang, H.; Jie, Y.; Yu, Y. Generation of 3D random meso-structure of soil-rock mixture and its meso-structural mechanics based on numerical tests. J. Cent. South Univ. 2015, 22, 619-630. [CrossRef]

26. Meng, Q.X.; Wang, H.L.; Xu, W.Y.; Cai, M. A numerical homogenization study of the elastic property of a soil-rock mixture using random mesostructure generation. Comput. Geotech. 2018, 98, 48-57. [CrossRef]

27. Guo, P.; Stolle, D.F.E. A physically meaningful homogenization approach to determine equivalent elastic properties of layered soil. Can. Geotech. J. 2018, 55, 303-311. [CrossRef]

28. Jellali, B.; Bouassida, M.; de Buhan, P. A homogenization method for estimating the bearing capacity of soils reinforced by columns. Int. J. Numer. Anal. Methods Geomech. 2005, 29, 989-1004. [CrossRef]

29. Abdelkrim, M.; de Buhan, P. An elastoplastic homogenization procedure for predicting the settlement of a foundation on a soil reinforced by columns. Eur. J. Mech. A Solids 2007, 26, 736-757. [CrossRef] 
30. Ching, J.; Hu, Y.G.; Phoon, K.K. Effective young's modulus of a spatially variable soil mass under a footing. Struct. Saf. 2018, 73, 99-113. [CrossRef]

31. Zimmermann, T.; Sarf, J.; Truty, A.; Podles, K. Numerics for geotechnics and structures. Recent developments in ZSoil.PC. In Applications of Computational Mechanics in Geotechnical Engineering V; Taylor \& Francis: Abingdon, UK, 2007.

32. Commend, S.; Kivell, S.; Obrzud, R.; Podleś, K.; Truty, A.; Zimmermann, T. Computational Geomechanics. Getting Started with ZSOIL.PC, 5th ed.; Rossolis Editions: Preverenges, Switzerland, 2018.

33. Truty, A. On consistent nonlinear analysis of soil-structure interaction problems. Stud. Geotech. Mech. 2018, 40, 19. [CrossRef]

34. Python Software. Python 2.7.17. 2019. Available online: https://www.python.org/downloads/release/python-2717/ (accessed on 30 June 2021).

35. Winkelmann, K.; Żyliński, K.; Górski, J. Probabilistic analysis of settlements under a pile foundation of a road bridge pylon. Soils Found. 2021, 61, 80-94. [CrossRef]

36. Winkelmann, K.; Zabuski, L.; Przewłócki, J.; Górski, J. Reliability-based stability analysis of a baltic cliff by the combined response surface method. Geotech. Geol. Eng. 2020, 38, 5549-5563. [CrossRef]

37. Grigoriu, M. Algorithm for generating samples of homogeneous gaussian fields. J. Eng. Mech. 2003, 129, 43-49. [CrossRef]

38. Bielewicz, E.; Górski, J. Shells with random geometric imperfections simulatiom-Based approach. Int. J. Non. Linear. Mech. 2002, 37, 777-784. [CrossRef]

39. Górski, J.; Mikulski, T.; Ozie „bło, M.; Winkelmann, K. Effect of geometric imperfections on aluminium silo capacities. Stahlbau 2015, 84, 52-57. [CrossRef]

40. Tejchman, J.; Górski, J. Modeling of bearing capacity of footings on sand within stochastic micro-polar hypoplasticity. Int. J. Numer. Anal. Methods Geomech. 2011, 35, 226-243. [CrossRef]

41. Knabe, W.; Przewłocki, J.; Rózyński, G. Spatial averages for linear elements for two-parameter random field. Probab. Eng. Mech. 1998, 13, 147-167. [CrossRef]

42. Chan, C.L.; Low, B.K. Practical second-order reliability analysis applied to foundation engineering. Int. J. Numer. Anal. Methods Geomech. 2012, 36, 1387-1409. [CrossRef]

43. Ovesen, N.K. Assessment of characteristic values of soil parameters for design. In Proceedings of the XIII Conference on Soil Mechanics and Foundation Engineering, New Delhi, India, 5-10 January 1994; pp. 427-460.

44. Cherubini, C. Data and consideration on the variability of geotechnical properties of soils. In Proceedings of the ESREL Conference, Lisbon, Portugal, 17-20 June 1997; pp. 1538-1591.

45. Campbell, J.B. Spatial variability of soils. Ann. Assoc. Am. Geogr. 1979, 69, 544-556. [CrossRef] 